\title{
Relationship between the presence of abnormal hallux interphalangeal angle and risk of ingrown hallux nail: a case control study
}

\author{
Antonio Córdoba-Fernández ${ }^{*}$ Pedro Montaño-Jiménez and Manuel Coheña-Jiménez
}

\begin{abstract}
Background: Many risk factors have been identified to be associated with ingrown toenail. Internal pressure by the distal phalanx of the hallux and the second toe and external compression from the shoes has been proposed as a reason for the pathology. The main objective of the study was to analyze the existence of a correlation between the presence of pathological hallux interphalangeal angle (HIA) and risk of ingrown hallux nail.

Methods: One hundred and sixty-five subjects (312 ft) were enrolled in a cross-sectional, analytical and observational case-control study. A radiographic computerized system was used to measure HIA in both groups. The angle was considered as the sum of three angles, obliquity, asymmetry and joint deviation.

Results: The mean HIA in case group subjects (patients with hallux ingrown nail) was significantly higher than that obtained in control group subjects $\left(17.39 \pm 6.0^{\circ}\right.$ versus $\left.13.47 \pm 4.6^{\circ}, p=.036\right)$. A total of 73.71 and $46.79 \%$ of feet presented an angle equal or greater than $13.47^{\circ}$ in the onychocryptosis and control group, respectively.

Conclusions: The results show a correlation between the variables analysed. The presence of an HIA greater or equal than $14.5^{\circ}$ may be a predisposing factor for developing onychocryptosis of the hallux. Clinicians treating individuals with pathology in hallux might use a baseline cutoff of HIA equal than $13.5^{\circ}$.
\end{abstract}

Keywords: Hallux valgus interphalangeus, Onychocryptosis, Interphalangeal angle, Ingrown hallux nail

\section{Background}

Ingrown toenail or onychocryptosis is a common problem in routine clinical practice which leads to pain and disability. Several risk factors have been identified as associated with the pathogenesis. Extrinsic risk factors including improperly trimmed nails, tight or poorly shaped shoes, abnormal nail shape, and hyperhidrosis have been associated with the pathology [1-3]. Intrinsic risk factors (congenital and heredity) have been also related to the pathology. Studies have noted anatomical abnormalities or certain forefoot shape as possible risk factors in developing ingrown toenail. Some authors have emphasized the internal pressure role that the distal phalanx on the lateral edge of the nail could play in developing onychocryptosis. Biomechanical imbalance between the great toe and the second toe in an ill-fitting shoe is the most commonly cited theory in the

\footnotetext{
* Correspondence: acordoba@us.es

* Correspondence: acordoba@us.es Sevilla 41009 Spain
}

etiology. Some studies report a higher prevalence in people in which the first toe is shorter than the second toe (Greek foot) and also in people in whom the first and second toes are equal in length, but in whom the first metatarsal is shorter than the second (squared index minus foot type) $[4,5]$. However, other authors found a higher prevalence of onychocryptosis in subjects in which the hallux is longer than the second toe (Egyptian feet types) [6].

Although many causes have been suggested based on clinical experience, current evidence suggests that the most probable cause is a combination of at least three of these factors $[7,8]$. Few studies have analyzed the association between abnormal hallux interphalangeal angle (HIA) and onychocryptosis with controversial results $[8,9]$. The main objective of the study was to analyze by a cross-sectional, analytical and observational casecontrol study the existence of a correlation between onychocryptosis and the presence of pathological hallux interphalangeal angle (HIA). 


\section{Materials and methods Subjects}

The required sample size was calculated using the software $\mathrm{G}^{*}$ Power 3.1.3, assuming an alpha error of 5 and a beta error of $5 \%$ to estimate the difference between 2 independent samples using one-tailed tests and with a large effect size $(d>0.8)$. The result was that a minimum of 21 cases per group was necessary. The work was carried out between February 2011 and March 2013 and was approved by the Research Ethics and Experimental Committee of the Universidad de Sevilla. The study involved a total of one hundred and sixty five subjects who were treated in the Área Clínica de Podología de la Universidad de Sevilla. The participants were patients who satisfied the inclusion criteria and gave their written informed consent to voluntarily participate in the study. The final study sample consisted of three hundred and twelve great toes from 165 subjects (63 men and 102 women; mean \pm SD age, $26.3 \pm 9.3$ year). Both groups were homogeneous in regard to the age variable (median age was not statistically different between the groups, $p=.08$ ). Statistically significant differences were found regarding the distribution of $\operatorname{sex}(p=.008)$. The characteristics and distribution of the study population are listed in Table 1.

\section{Selection criteria}

Eighty-four subjects were selected consecutively for the study group from among patients attending with proven unilateral or bilateral hallux ingrown toenail of all grades, and 81 for the control group selected among podiatry healthy student without history of previous onychocryptosis or another forefoot deformities. Exclusion criteria were: presence of hallux abductus valgus, obvious clinical deformity of the hind and midfoot or prior existence of osteoarticular surgery or severe trauma that could have altered the morphology of the forefoot.

\section{Procedure}

All participants were subjected to dorso-plantar $\mathrm{x}$-ray (standing) view for both feet. All subjects underwent the same radiological protocol using a radiological computerized system (Kodak Point-of-Care CR 140 System $^{\circ}$ ) which enabled increased image up to $300 \%$ with greater accuracy to score the points that determine the medial

Table 1 General Features of patients

\begin{tabular}{llll}
\hline & Control group & Study group & Total analysed \\
\hline Toes & $156(50 \%)$ & $156(50 \%)$ & 312 \\
Males & 37 & 26 & 63 \\
Females & 44 & 58 & 102 \\
Average age & 27.19 & 25.35 & 26.27 \\
Standard deviation & 9.48 & 9.04 & 9.26 \\
Median (range) & $23(12-50)$ & $23(10-50)$ & $23(10-50)$ \\
\hline
\end{tabular}

axis of the metatarsal and phalangeal explored. The study protocol contained the following variables: age, sex, side, digital formula, ingrowing edge affected, first or recurrent presentation. The angles measured on the $x$-ray were HIA and hallux abductus valgus angle (HAVA) to rule out the existence of hallux valgus. Subjects who had HAVA equal to or greater than $15^{\circ}$ were excluded from the study. The radiological examination was conducted by two blinded researchers to the physical findings. Measurements was performed according to the method proposed by Sorto et al. (Figs. 1, 2 and 3) such that the angle resulting angle had to be equal to the sum of the three angles obliquity, asymmetry and joint deviation. The interobserver and intraobserver reliabilities of the two researchers and the angles measurements were assessed by calculating the intraclass correlation coefficient (ICC) with confidence interval (CI) $95 \%$. The intraobserver reliability was measured with an interval of one week. Any value above $13.4^{\circ}$ for HIA was considered abnormal. Data were analyzed using SPSS Version 21 (SPSS Inc, Chicago, IL).

\section{Results}

The results of the measurements determined that the average value of the HIA from the study group was significantly higher than the control group $(p=.036)$ (Table 2). The percentage of subjects with HIA higher than $13.47^{\circ}$ was 73.71 and $46.79 \%$ for the study and control group,

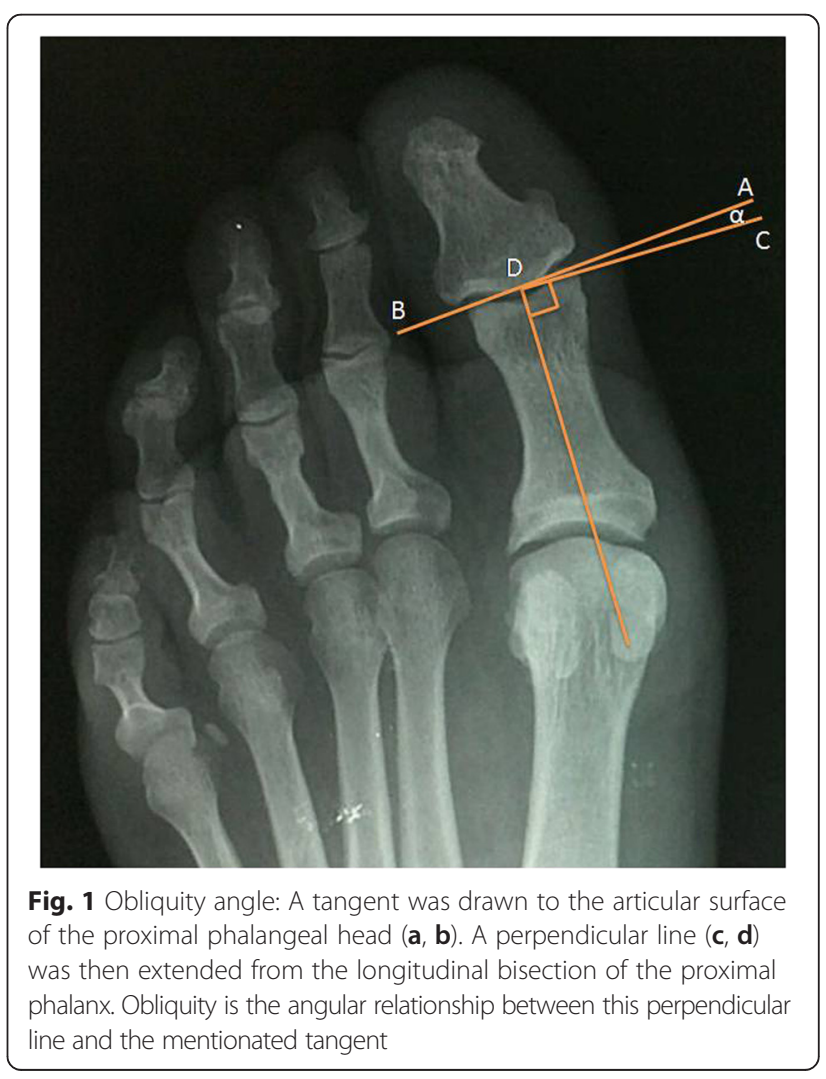




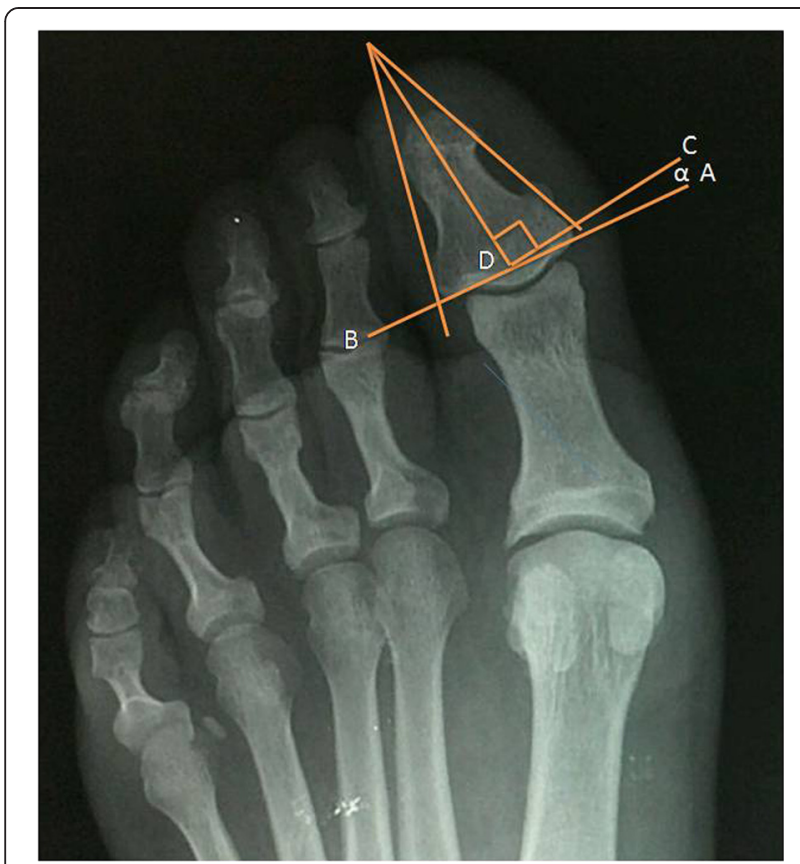

Fig. 2 Assimmetry angle: A tangent was drawn to the articular surface of the distal phalangeal base $(\mathbf{a}, \mathbf{b})$. A perpendicular line $(\mathbf{c}, \mathbf{d})$ was then extended from the longitudinal bisection of the distal phalanx. Assymmetry is the angular relationship between this perpendicular line and the above mentionated tangent $(A B C)$

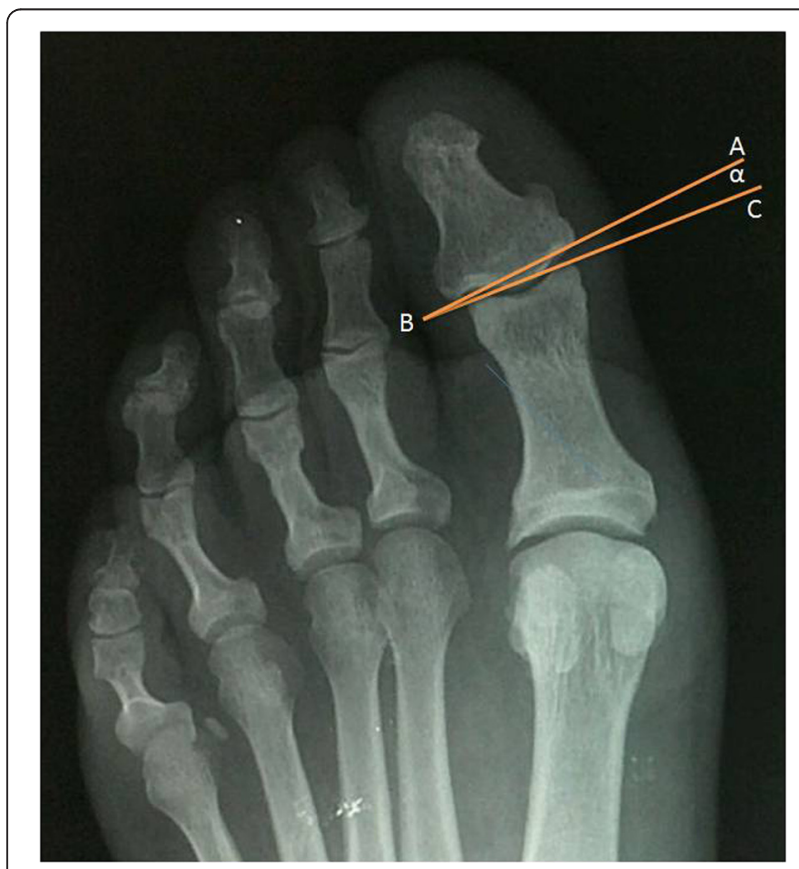

Fig. 3 Joint deviation angle: Tangents were drawn to articular surfaces of the distal phalangeal base $(\mathbf{a}, \mathbf{b})$ and the proximal phalangeal head $(\mathbf{c}, \mathbf{b})$. Joint deviation is the angular relationship between these two tangents $(A B C)$
Table 2 Comparison of the mean HIA between groups ( $N=312$ toes, 165 patients)

\begin{tabular}{llll}
\hline Degrees & $\begin{array}{l}\text { Control } \\
\text { group }\end{array}$ & Onychocryptosis & $P$ \\
\hline Median (minimum, maximum) & $(12.73,14.20)$ & $(16.44,18.33)$ & \\
Mean \pm SD & $13.47 \pm 4.66$ & $17.39 \pm 6.00$ & $.036^{a}$ \\
Typical mean error & .374 & .481 & \\
$95 \%$ Cl (lower limit, upper & $(12.73-14.20)$ & $(16.44-18.33)$ & \\
limit) & & & \\
\hline
\end{tabular}

astudent $t$ test; $\mathrm{Cl}(95 \%)$

respectively. The percentage of individuals in the study group with $\mathrm{HIA} \geq 15^{\circ}$ was $69.72 \%$. No statistically significant differences were recorded in regard to the average HIA in the study group according to sex (Table 3). The maximum average value of HIA in the study group was recorded for the interval of subjects aged between 21-30 years old and the minimum average value aged 41-50 years old (Table 4 ) with statistically significant differences between age intervals $(P<.05)$. The Anova test found statistically significant differences in regard to the HIA according to the age range in both groups $(p<.001)$. The Scheffe multiple comparisons test determined the existence of statistically significant differences in regard to the HIA $(p=.002)$ recorded between the two age ranges 2130 and 41-50 (Table 5). The ICC for intraobserver reliability was 0.96 and for interobserver reliability was 0.92 . In regard to the frequency of nail edge affected, $50.64 \%$ of those from the study group had both folds affected, 42.95 just the lateral edge and just $6.41 \%$ for the medial edge. $\mathrm{Ax} \mathrm{X}^{2}$-Pearson correlation coefficient with continuity correction revealed there is no relationship between the existence of a pathological HIA $\left(\geq 13.47^{\circ}\right)$ and the affected nail edge (Table 6). In regard to the kind of digital formula recorded for those from the study group, the Egyptian foot digital formula was the most prevalent with $64.10 \%$ of individuals followed by $25 \%$ of individuals with a Greek foot formula and $10.90 \%$ with square foot formula.

\section{Discussion}

Traditionally hallux abductus interphalangeus or valgus deformity has been defined as an increase in the HIA of greater than $10^{\circ}[10,11]$. Existing prior studies have revealed that the existence of an abnormal HIA may be related to the risk of suffering from ingrown hallux nail. In a

Table 3 Distribution of the mean of HIA in the study group according to sex

\begin{tabular}{llll}
\hline & Mean \pm SD & Typical mean error & $\begin{array}{l}\text { Lower-upper } \\
\text { limit }\end{array}$ \\
\hline Males (63 subjects) & $15.59 \pm 6.31$ & .42 & $14.49-16.16$ \\
Female (102 subjects) & $15.33 \pm 5.30$ & .50 & $14.59-16.58$ \\
\hline N 156 toes, 84 patients, $P .280 ;$ Cl (95\%) & &
\end{tabular}

$N 156$ toes, 84 patients, $P$.280; Cl (95\%) 
Table 4 Means distribution of HIA values for both groups included according to age group analysed

\begin{tabular}{lcc}
\hline & Study group & Control group \\
\hline Age intervals & & \\
$10-20$ years & $15.64 \pm 4.57$ & $13.95 \pm 3.58$ \\
$21-30$ years & $18.67 \pm 6.72$ & $14.71 \pm 5.19$ \\
$31-40$ years & $18.17 \pm 4.21$ & $10.92 \pm 4.06$ \\
$41-50$ years & $14.69 \pm 6.82$ & $11.74 \pm 4.16$ \\
\hline Data are presented as mean \pm SD $(95 \%$ confidence interval) &
\end{tabular}

case-control study on a sample of 80 patients, Darwish et al. analyzed the HIA and HAVA in subjects with onychocryptosis in the hallux (cases) and compared this with 80 healthy subjects (controls). As in our work, the percentage of abnormal HIA in the study group was also significantly higher (85\%) compared to just $25 \%$ in the control group $(p<.005)$. In the same way, the authors also found statistically significant differences $(p<.005)$ when they analyzed the HIA of patients with prior episodes of ingrown hallux nail in just one of the toes and compared this with the healthy contralateral toe that had never suffered from onychocryptosis. The study concluded that the existence of abnormal HAVA and HIA represents a risk factor for the pathogenesis of onychocryptosis of the hallux [9].

Conversely, in a retrospective study performed by Kose et al. the $\mathrm{x}$-rays of 81 patients with onychocryptosis were studied and compared to those of 100 healthy subjects. The HAVA, HIA and intermetatarsal angles (IMA) were measured; no statistically significant differences were found between the groups in regard to any of the three angles assessed. The average HIA value obtained in the case group was slightly higher but without any statistically significant differences $\left(11.9^{\circ} \pm 4.1\right.$ vs. $\left.12.0^{\circ} \pm 5.1 ; p=.123\right)$. The authors conclude that the study results do not reveal a correlation between forefoot misalignments and the existence of onychocryptosis, and they suggest that management of the pathology should not be based on correction of forefoot misalignments but rather managing the pathology itself [8].

In both studies, the authors set out as normal HIA values those that do not exceed $10^{\circ}$ and that has been considered a reference value for adults subjects in most

Table 5 Comparisons of the mean HIA performed within the different age groups in the study group

\begin{tabular}{lll}
\hline Variable & Mean of difference & $P$ value \\
\hline Age group of 21-30 & & .69 \\
VS $10-20$ & 2.02 & .100 \\
VS $31-40$ & 2.36 & .002 \\
VS $41-50$ & 4.02 & \\
\hline
\end{tabular}

* Scheffe test of multiple comparisons; Cl (95\%)
Table 6 Contingency table between abnormal HIA and nail edge affected

\begin{tabular}{|c|c|c|c|c|c|}
\hline & & & Lateral & Nail edge medial & Total \\
\hline \multirow[t]{4}{*}{$\mathrm{HIA}$} & $<13.47^{\circ}$ & Recount & 4 & 37 & 41 \\
\hline & & Expected frequency & 2.6 & 38.4 & 41 \\
\hline & $\geq 13.47^{\circ}$ & Recount & 6 & 109 & 115 \\
\hline & & Expected frequency & 7.4 & 107.6 & 115 \\
\hline \multirow[t]{2}{*}{ Total } & & Recount & 10 & 146 & 156 \\
\hline & & Expected frequency & 10 & 146 & 156 \\
\hline
\end{tabular}

studies performed [10, 12, 13]. However, this value does not correspond to observational studies performed on the general population; in fact, other authors establish mean reference values above $10^{\circ}$. Barnett in a study performed on 346 x-ray from feet in 173 British healthy subjects (mean age: 21.4 year) with shoes set out as mean HIA values for men $13^{\circ} \pm 3.72$ for the left foot; $13.1^{\circ} \pm 2.34$ for the right foot; and in women $13.3^{\circ} \pm 3.54$ for the left foot and $13.5^{\circ} \pm 3.53$ for the right foot [14] Sorto et al. determined a mean HIA value in $\mathrm{x}$-rays from $100 \mathrm{ft}$ in subjects of different ages and for both sexes of $13.4^{\circ}$ and they considered feet with HIA above this value as pathological [15].

The main aim of our work was to determine whether there is a direct correlation between the existence of ingrown hallux nail and the presence of a pathological HIA. Therefore, we have used a more precise system of measuring HIA than that used in prior studies. The mean HIA value obtained in the study group was significantly higher than the control group. The results indicate to us that it is difficult for a subject with HIA values $\geq 15.5^{\circ}$ not to suffer or be a future sufferer of onychocryptosis in the great toe. This highlights the impact of abnormal HIA on the onset of ingrown hallux nail. The authors recommend appropriate follow-up of these subjects to assess need for realignment surgery.

In the study performed by Darwish et al., the measurement technique used may have caused significant margins of error in measuring the angles studied, because these were performed with manual markers and rulers [9]. In the same way, in the study by Kose et al. the angles were measured by a collaborator outside the study, but without specifying the method used for this measurement [8]. The results obtained in this study are supported by the measurement technique used to measure the different angles. Barnett attributed the angular relationship between the longitudinal bisections of the distal and proximal phalanges of the great toe to two factors: an oblique orientation of the articular surface of the head of the proximal phalanx (obliquity), and an asymmetrical form of the distal phalanx itself (asymmetry) [14]. For Sorto et al. and Duke et al. the HIA value is in turn the sum of the three angles; 
angle of obliquity, asymmetry and combined joint deviation (angular relationship between the articular surfaces of the base of the distal phalanx and head of the proximal phalanx) which have been appropriately taken into consideration to perform this work $[15,16]$. Farber et al. revealed that measuring certain angles on $\mathrm{x}$-rays using a digital system is fully valid and leads to improving inter and intraobserver reliability in comparison with the use of the analogous technique by means of goniometer and pencil [17]. The program used in this work has the property of increasing the image size by zoom without distorting it; this enables reducing the margin of error when we mark the points that serve as a reference to determine the mean axis of the phalanges.

The possible relationship of HIA with age was part of a secondary aim that we had not set in this study. The age range with a higher HIA value was $21-30$ and the lower value $41-50$. In regard to sex no statistically significant differences were found in regard to HIA values recorded in both groups. In regard to the digital formula, we found that $64 \%$ of the patients in the study group had a Greek foot digital formula. These results coincide with those reported by Viladot and are substantially different to those obtained by Günal et al. [4, 18]. We agree with the first author who found more pathological changes in the forefoot of patients with Egyptian feet. For the interphalangeal hallux deformity not only does this lead to deformity in the transverse plane but also in the frontal plane, which also causes more compromise of space with footwear in people with Egyptian foot digital formula. We consider therefore that individuals with Greek foot or square digital foot are less at risk of suffering from forefoot pathologies because of the footwear as a consequence of the lower vulnerability of these to the standard triangular form of the shoe tip which facilitates better accommodation of the foot to the footwear.

In regard to the frequency of nail edge affected, in the study of Darwish et al. the $85 \%$ of patients in the study group had affected the lateral edge [9]. Kose et al. excluded patients in their study group with medial or bilateral ingrowing nail edge [8]. Günal et al. did not report any information regarding affected percentage of edges although reports that patients treated with a spacer between the first and second toes healed in about three weeks [4]. We have found that more than half of the patients in our study group had affected both nail edges. Overall the lateral edge was affected by more than $93 \%$ of cases.

The findings of this work are based on by a crosssectional, analytical and observational case-control study, however, the limited population and the presence of others common risk factor related with the pathology may have introduced a selection bias. Future research should focus on validating the results of this study, a prospective study looking at the feet of an unaffected populations and then observing whether patients with increased HIA developed ingrown toenails would be definitive.

\section{Conclusion}

The results of our study have revealed the correlation existing between the main variables; it is verified that patients that present increased HIA values are more likely to develop ingrown hallux nail. We can therefore state that among the possible etiological causes of onychocryptosis, the existence of a pathological HIA plays a substantial role in the genesis of the pathology. The presence of an HIA greater or equal than $14.5^{\circ}$ may be a predisposing factor for developing ingrown hallux nail. The results indicate to us that it is difficult for a subject with HIA values $\geq 15.5^{\circ}$ not to suffer or be a future sufferer of onychocryptosis. This approach can enable clinicians to better design treatment programs to minimize the risk. Clinicians treating individuals with ingrown hallux nail may use this baseline cutoff of HIA as one of the indicators of risk. The results of this study suggest that in subjects with HIA angle $\geq$ $15.5^{\circ}$ affected by other associated risk factors should be followed. If the pathology recurs after conservative or surgical procedures in the nail unit, it will highlight the need for alignment procedure.

\section{Abbreviations \\ HIA: Hallux interphalangeal angle; HAVA: Hallux abductus valgus angle; ICC: Intraclass correlation coefficient; Cl: Confidence interval; \\ IMA: Intermetatarsal angle.}

\section{Competing interests}

The authors declare that they have no competing interests.

\section{Authors' contributions}

All authors were fully involved in the preparation of the study procedures. The material within has not been and will not be submitted for publication elsewhere. All authors read and approved the final draft of the manuscript.

\section{Acknowledgements}

This work was supported by grants from the Departamento de Podología and Área Clínica de Podología de la Universidad de Sevilla (Spain)

Received: 20 July 2015 Accepted: 3 October 2015

Published online: 15 October 2015

\section{References}

1. DeLauro NM, DeLauro TM. Onychocryptosis. Clin Podiatric Med Surg. 2004;21(4):617-30.

2. Heidelbaugh JJ, Lee $H$. Management of the ingrown toenail. Am Fam Physician. 2009:79(4):303-8.

3. Parrinello JF, Japour C, Dykyj D. Incurvated nail: does the phalanx determine nail plate shape? J Am Podiatr Med Assoc. 1995;85(11):696-8.

4. Gunal I, Kosay C, Veziroglu A, Balkan Y, Ilhan F. Relationship between onychocryptosis and foot type and treatment with toe spacer. A preliminary investigation. J Am Podiatric Med Assoc. 2003:93(1):33-6.

5. Langford DT, Burke C, Robertson K. Risk factors in onychocryptosis. Br J Surg. 1989;76(1):45-8.

6. Ogawa R, Hyakusoku H. Does Egyptian foot present an increased risk of ingrowntoenail? Plast Reconstr Surg. 2006;117(6):2111-2. doi:10.1097/ 01.prs.0000214750.33936.45. 
7. Eekhof JA, Van Wijk B, KnuistinghNeven A, Van der Wouden JC. Interventions for ingrowing toenails. Cochrane Database Syst Rev. 2012;18(4):CD001541. doi:10.1002/14651858.CD001541.

8. Kose $\mathrm{O}$, Celiktas M, Kisin B, Ozyurek S, Yigit S. Is there a relationship between forefoot alignment and ingrown toenail? A case-control study. Foot Ankle Spec. 2011:4(1):14-7. doi:10.1177/1938640010382293.

9. Darwish FM, Haddad W, Ammari F, Aoudat Z. Association of abnormal foot angles and onychocryptosis. Foot (Edinb). 2008;18(4):198-201. doi:10.1016/ j.foot.2008.05.004.

10. Gentili A, Masih S, Yao L, Seeger LL. Pictorial review: foot axes and angles. Br J Radiol. 1996;69(826):968-74.

11. Hetherington V. Hallux Valgus and Forefoot Surgery. New York: Churchill Livingston; 1994

12. Castillo-López JM, Ramos-Ortega J, Reina-Bueno M, Domínguez-Maldonado G, Palomo-Toucedo IC, Munuera PV. Hallux abductus interphalangeus in normal feet, early stage hallux limitus, and hallux valgus. J Am Podiatr Med Assoc. 2014:104(2):169-73. doi:10.7547/0003-0538-104.2.169.

13. Park JY, Jung HG, Kim TH, Kang MS. Intraoperative incidence of hallux valgus interphalangeus following basilar first metatarsal osteotomy and distal soft tissue realignment. Foot Ankle Int. 2011;32(10):1058-62.

14. Barnett $\mathrm{CH}$. Valgus deviation of the distal phalanx of the great toe. J Anat. 1962;96(2):171-7.

15. Sorto LA, Balding MG, Weil LS, Smith SD. Hallux abductusinterphalangeus. Etiology, x-ray evaluation and treatment.1975. J Am Podiatr Med Assoc. 1992;82(2):85-97.

16. Duke H, Newman LM, Bruskoff B, Daniels R. Hallux abductus interphalangeus and its relationship to hallux abductus valgus. J Am Podiatr Med Assoc. 1982;72(12):625-8.

17. Farber DC, Deorio JK, Steel MW. Goniometric versus computerized angle measurement in assessing hallux valgus. Foot Ankle Int. 2005:26(3):234-8.

18. Viladot A. Metatarsalgia due to Biomechanical alterations of the forefoot. Orthop Clin North Am. 1973;4(1):165-78

\section{Submit your next manuscript to BioMed Central and take full advantage of:}

- Convenient online submission

- Thorough peer review

- No space constraints or color figure charges

- Immediate publication on acceptance

- Inclusion in PubMed, CAS, Scopus and Google Scholar

- Research which is freely available for redistribution 